\title{
Atuação da fisioterapia para a redução do tempo no trabalho de parto vaginal
}

O parto é apontado como um dos acontecimentos mais marcantes na vida de uma mulher, podendo influenciar de forma emocional e física durante toda sua vida. o fisioterapeuta é o profissional mais indicado para fazer o acompanhamento da gestante, diminuindo o tempo de trabalho de parto e da percepção dolorosa. Este artigo de revisão tem como objetivo analisar a atuação da fisioterapia durante o parto humanizado. Foi realizada pesquisa de revisão metodológica no período de janeiro e fevereiro de 2018, e foram selecionados artigos que estavam relacionados ao tema proposto. Para isso, realizou-se um levantamento bibliográfico nas bases de dados PUBMED, LILACS, SCIELO. A utilização de banhos quentes para o alivio da dor durante o trabalho de parto constituem um dos métodos nãofarmacológicos mais utilizados na progressão e na evolução do parto natural. A fisioterapia contribui diminuindo a tríade medo-tensão-dor, promovendo reeducação da função respiratória, o restabelecimento da função intestinal, estimulando o sistema circulatório, promovendo analgesia e favorecendo o parto.

Palavras-chave: Dor; Trabalho de parto; Fisioterapia; Parto humanizado.

\section{Physiotherapy for the reduction of time in vaginal labor}

Childbirth is regarded as one of the most striking events in a woman's life and can influence in an emotional and physical way throughout her life. The physiotherapist is the most appropriate professional to follow up the pregnant woman, reducing labor time and painful perception. This review article aims to analyze the performance of physiotherapy during humanized delivery. Methodological review was carried out in January and February of 2018, and articles were selected that were related to the proposed theme. For this, a bibliographic survey was carried out in the databases PUBMED, LILACS, SCIELO. The use of hot bath for the relief of pain during labor is one of the most widely used non-pharmacological methods for the progression and evolution of natural childbirth. Physiotherapy contributes by reducing the fear-tension-pain triad, promoting re-education of the respiratory function, restoration of the intestinal function, stimulating the circulatory system, promoting analgesia and favoring delivery.

Keywords: Pain; Labor; Physiotherapy; Humanized birth.

Topic: Fisioterapia

Reviewed anonymously in the process of blind peer.

Clorismar Bezerra de Sousa

Faculdade Guaraí, Brasil

http://lattes.cnpq.br/1697978820400324

cloressousa@hotmail.com

Itainara Márcia Antunes da Silva

Faculdade Guaraí, Brasil

http://lattes.cnpq.br/1428922744087927

itainara202004@gmail.com

Ramon Sales Costa

Faculdade Guaraí, Brasil

http://lattes.cnpq.br/7486657294477848

ramonfd714@gmail.com

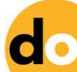

DOI: 10.6008/CBPC2236-9600.2018.002.0013
Received: $\mathbf{2 1 / 0 8 / 2 0 1 9}$

Approved: 29/08/2019
Vilmaci Santos de Souza Pereira

Faculdade Guaraí, Brasil

http://lattes.cnpq.br/5037819653029257

vilmacisantos2016@gmail.com

\section{Referencing this:}

SOUSA, C. B.; SILVA, I. M. A.; PEREIRA, V. S. S.. Atuação da fisioterapia para a redução do tempo no trabalho de parto vaginal. Scire Salutis, v.8, n.2, p.123-128, 2018. DOI: http://doi.org/10.6008/CBPC2236$\underline{9600.2018 .002 .0013}$ 


\section{INTRODUÇÃO}

O parto via vaginal foi reintroduzido há, pelo menos, três décadas, e houve esforços mundiais para que ocorresse a liberdade corporal durante o trabalho de parto. O Brasil está entre os países que tem o maior índice de partos cesarianos no mundo (FAÚNDES et al., 2001). O Ministério da Saúde no ano de 2000 lançou um programa de humanização do parto e nascimento, implementando condutas fundamentadas em evidências científicas, com o objetivo de incentivar o parto vaginal recuperando a participação ativa das gestantes de baixo risco (BIO et al., 2006).

A dor durante o parto é uma das razões que levam ao aumento dessa incidência, promovendo, assim, fisiologicamente a ideia que a vagina e o períneo se mantém intactos (FAÚNDES et al., 2001), na procura de estimular o parto humanizado de uma forma menos agressiva e mais natural, considerando mais adequada a fisiologia do parto, visto que o parto medicalizado se tornou muito artificial e violento (FLOYD et al.,1992)

O parto vaginal divide-se em três etapas: a primeira consiste na contração uterina e uma dilatação do colo, facilitando a saída do feto; na segunda, acontece a expulsão do feto; e a terceira etapa finaliza com a expulsão da placenta e da bolsa de líquido amniótico de forma espontânea. Sendo assim, analisamos a importância das condutas cinesioterapêuticas no trabalho pré parto, visando a coordenação dos músculos do assoalho pélvico, para que a parturiente saiba a forma correta de relaxar e expulsar o bebê (BARACHO, 2007)

Segundo Rezende et al. (2006), a fase latente dura em média 20 horas nas primíparas e 14 horas nas multíparas. 0 parto propriamente dito (fase ativa) tem período de dilatação, e se completa em cerca de 12 horas, nas primíparas e de 7 horas nas multíparas. A expulsão leva, respectivamente, 50 e 20 minutos. Todavia, empregando assistência ativa, a parturição, na maioria dos partos normais, ocorre dentro de seis horas.

A fisioterapia obstétrica presta assistência às gestantes de baixo risco, visando ativamente o uso do próprio corpo, sendo assim um fator estimulante para a conscientização corporal da parturiente, fazendo com que essa experiência seja satisfatória no processo de trabalho de parto (BIO et al., 2006, citado por BAVARESCO et al., 2011)

Este artigo de revisão tem como objetivo analisar a atuação da fisioterapia durante o parto humanizado com as seguintes abordagens terapêuticas: massagem, agachamento, deambulação, TENS, crioterapia, banhos quentes e exercícios com bola suíça. Com essas opções de condutas o terapeuta realizara na hora do parto alternâncias de decúbitos, deambulação pelo quarto ou colocar na posição de cócoras conforme a necessidade da gestante durante tal procedimento.

Os objetivos desses recursos fisioterapêuticos são: reeducar a função respiratória, restabelecer a função intestinal, estimular o sistema circulatório, promover analgesia e favorecer a orientação postural. Favorecendo conforto e melhora na condição física da puérpera (LEVITT et al., 2004, citado por SANTANA et al., 2011). 


\section{METODOLOGIA}

A presente pesquisa trata-se de uma revisão de literatura que busca demostrar a contribuição da fisioterapia na redução do tempo de trabalho de parto. A busca dos dados foi realizada no período de janeiro e fevereiro de 2018, foram selecionados artigos que estavam relacionados ao tema proposto. Para isso, realizou-se um levantamento bibliográfico nas bases de dados PUBMED, LILACS, SCIELO. Foram utilizados as palavras-chave 'Fisioterapia', 'Parto Humanizado', 'Gestante' e 'Dor'. A pesquisar incluiu apenas estudos no período de 2008 a 2018, nacionais e na literatura estrangeira, e foram excluídos os artigos que não tinham fundamentação científica ou que não estavam relacionados com o tema. Com o auxílio dos descritores, foram encontrados 23 artigos desses 11 artigos foram selecionados para o estudo.

\section{DISCUSSÃO TEÓRICA}

A valorização do fisioterapeuta, na assistência à mulher em trabalho de parto, vem aumentando cada dia mais. As gestantes que fizeram uso de suas técnicas e recursos relataram algum tipo de melhora, seja no alívio da dor, seja no relaxamento ou na diminuição dos estágios de parto, além de recuperar uma participação mais ativa da parturiente em todo o processo do parto (STEPHENSON et al., 2004). Essas técnicas podem ser treinadas pelo fisioterapeuta através da cinesioterapia, na qual é ensinada às gestantes com o intuito de aumentar o relaxamento, permitindo que a gestante colabore durante todas as fases do parto. Nas condutas de cinesioterapia são realizadas exercícios com bastão e bola, exercícios de anteversão e retroversão pélvica, exercícios ativos de membros superiores e inferiores (CASTRO et al., 2012).

Um dos exercícios bem utilizados é com a bola na posição vertical (sentada), onde favorece a musculatura do assoalho pélvico, principalmente os músculos levantadores do ânus, fáscia da pelve e pubo coccígeos. Proporcionando liberdade de mudança de posição à parturiente, e mantendo a participação ativa da mulher no processo do nascimento (SILVA, 2011).

As contrações expulsivas acontece de forma voluntária, ficando no comando da parturiente, intensificando-as ou abrandando-as. Para tanto, a parturiente requer mobilidade pélvica e o uso intensivo e voluntário da musculatura do abdômen, do períneo e do diafragma respiratório. Essas habilidades podem ser treinadas pelo fisioterapeuta através da cinesioterapia.

Pode se realizar as seguintes técnicas: respiração, controlada de forma voluntaria pela parturiente fornecendo oxigenação necessária ao feto, diminuindo a fadiga durante o trabalho de parto; técnicas de relaxamento, quebrando esse ciclo vicioso da dor, medo e tensão; o treino da expulsão, que se faz necessário para a gestante adquirir confiança para o momento do parto (POLDEM et al., 1997, citado por CANESIN et al., 2010).

Outro método é a massagem perineal, onde favorece a expansão do tecido perineal facilitando na hora do parto. A técnica pode ser realizada pela própria mulher, com os dedos indicadores, polegares, ou dedos médios, introduzindo-os na vagina e realizando movimentos oscilantes rítmicos em ' $U$ ' para cima, lateralmente na vagina, com pressão para baixo, estirando o períneo, de um lado a outro, sendo a frequência e a duração determinadas pelo terapeuta (POLDEM et al., 2000, citado por MARCELINO et al., 2008) 
A massoterapia onde posicionamos a paciente em decúbito lateral esquerdo ou deitada, e são realizados deslizamentos suaves e superficiais na região lombo sacra (CASTRO et al., 2012). Apesar de não haver comprovação da relação entre os riscos e benefícios da massagem durante o trabalho de parto, mas na prática, observa-se que essa técnica promove analgesia e diminui ansiedade, conduzindo a gestante de forma satisfatória ao trabalho de parto (BIO et al., 2006, citado por BAVARESCO et al., 2011).

Durante o parto normal, um grande obstáculo que é encarado é a dor, mas que pode ser vivenciado de forma positiva pela gestante e seus familiares. Para isso, há uma necessidade de mantê-la consciente para estar calma e relaxada; esse modo é indicado pelos pesquisadores as formas não-farmacológicas de alívio da dor (BAVARESCO et al., 2011, citado por OLIVEIRA et al., 2014).

A bola suíça é utilizada dentre as práticas humanizadas durante o trabalho de parto para que a gestante participe mais ativamente durante esse processo, onde irá promover uma melhora na percepção da tensão, fazendo com que a mulher adquira um relaxamento global, sendo uma das estratégias constituídas para a humanização no trabalho de parto (BAVARESCO et al., 2011, citado por OLIVEIRA et al., 2014).

A crioterapia irá causar uma vasoconstrição, sendo uma das formas mais remotas para promover a analgesia. As parturientes na hora do parto pode utilizar pacotes de gelo ou compressas frias para redução da dor e temperatura, agindo na diminuição do processo inflamatório, na redução de sangramento e do metalismo, promovendo assim a analgesia (BIO et al., 2006, citado por BAVARESCO et al., 2011).

A deambulação pode proporcionar a parturiente uma sensação de controle e domínio ao iniciar o trabalho de parto, além de promover uma distração e reduzir a utilização de analgesia e evitar o processo da cesariana (LAWRENCE et al., 2010, citado por PORTO et al., 2010). O estímulo à deambulação e às posturas ativas no parto também constituem uma estratégia de conforto e estão associados ao trabalho de parto menos demorado, sem repercussões danosas à mãe e ao bebê (SILVA, 2011).

Estudos têm revelado que, fisiologicamente, é muito melhor para a mãe e para o feto quando a mulher se mantém em movimento durante o trabalho de parto, pois o útero se contrai muito mais eficazmente, o fluxo sanguíneo que chega ao bebê através da placenta é mais abundante, o trabalho de parto torna-se mais curto e a dor é menos intensa (MAMEDE, 2007).

Um dos métodos bastante utilizado pelo fisioterapeuta na hora do parto com a parturiente são as técnicas respiratórias, que podem ser realizadas para proporcionar alivio de dor, relaxamento, aumentar a oxigenação da mãe como também à do bebê, melhora a concentração e reduz as chances de traumas perineal na mãe.

Dentre as numerosas técnicas de percepção respiratória, uma das mais conhecidas e a mais segura a nível fisiológico para o binômio mãe-filho, é a respiração profunda ou abdominal, na qual a parturiente realiza uma inspiração expandindo a parede abdominal descontraída, abaixando o diafragma. Logo em seguida, expira lentamente, contraindo os músculos abdominais, tendo os lábios em posição como se estivesse apagando uma vela. Tal exercício controla a velocidade da expiração, facilitando a contração dos 
músculos abdominais. No período de expulsão do feto a parturiente respira fundo e realiza uma apneia, fazendo força para expulsar o bebê relaxando a musculatura perineal (MAZZALI, 2008).

A utilização de banhos quentes para o alívio da dor durante o trabalho de parto constituem um dos métodos não farmacológicos mais utilizados na progressão e na evolução do parto natural. O banho quente é um método não invasivo de calor superficial e estimulação cutânea realizado a uma temperatura de $37^{\circ} \mathrm{C}$ que está associado a redução dos níveis de hormônios, promovendo o relaxamento e melhorando no padrão das contrações uterinas. A região mais apropriada para se aplicar o jato de água quente é a lombo sacral por um período de 30 minutos onde a parturiente irá escolher a melhor posição, em pé ou sentada (BARBIERI et al., 2013).

O recursos da eletroterapia utilizado na obstetrícia por fisioterapeutas é o TENS produzindo analgesia atuando na ativação de receptores sensoriais aumentando a endorfina e assim diminuindo a dor. Os parâmetros de intensidade e frequência dependem da sensibilidade e o estágio do parto da parturiente que devem ser aumentados ou diminuídos durante as contrações (BIO et al., 2006, citado por BAVARESCO et al., 2011). O posicionamento dos eletrodos durante a fase de dilatação deve ser colocado sobre a região para vertebral ente as vertebras t8 e I1 e região sacral S1 e S4, que correspondem aos receptores associados ao primeiro e ao segundo estágio do trabalho de parto (BIO et al., 2006, citado por BAVARESCO et al., 2011).

Segundo os Bavaresco et al. (2011), a abordagem fisioterapêutica tem como objetivo proporcionar técnicas e condutas terapêuticas que tragam como benefícios a redução do quadro álgico da parturiente recursos como cinesioterapia, massoterapia, banhos quentes, TENS, bola suíça, crioterapia, deambulação e técnicas de respiração, tais recursos auxiliaram na diminuição da percepção dolorosa, e explosão do feto (MACHADO et al., 2006; MOURA et al., 2007).

\section{CONCLUSÕES}

Com o lançamento do programa de humanização do parto e nascimento, a fisioterapia obstétrica veio para tornar o processo de parturição mais agradável e eficaz ao binômio mãe-filho, durante o trabalho de parto, no qual as técnicas de fisioterapia contribui diminuindo a tríade medo-tensão-dor, promovendo reeducação da função respiratória, o restabelecimento da função intestinal, estimulando o sistema circulatório, promovendo analgesia e favorecendo o parto.

\section{REFERÊNCIAS}

ABREU, N. S.; CRUZ, M. V.; GUERRA, Z. F.; PORTO, F. R.. Atenção fisioterapêutica no trabalho de parto e parto. Revista interdisciplinar de estudos experimentais, v.5, p.715, 2013.

BARBIERI, M.; HENRIQUE, A. J.; CHORS, F. M.; MAIA, L. N.; GABRIELLONI, M. C. Banho quente de aspersão, exercícios perineais com bola suíça e dor no trabalho de parto. Acta Paulista de Enfermagem, São Paulo, v.26, n.5, 2013.

BAVARESCO, G. Z.; SOUZA, R. S. O.; ALMEICA, B.; SABATINO, J. H.; DIAS, M. O.. O fisioterapeuta como profissional de suporte à parturiente. Ciências e Saúde Coletiva, Rio de Janeiro, v.16, n.7, p.3259-3266, 2011.

CANESIN, K. F.; AMARAL, W. N.. Atuação fisioterapêutica para diminuição do tempo de trabalho de parto: revisão de literatura. Femina, v.38, n.8, p.429-433, 2010.

CASTRO, A. S.; CASTRO, A. C.; MENDONÇA, A. C.. Abordagem fisioterapêutica no pré-parto: proposta de protocolo e avaliação da dor. Fisioterapia e pesquisa, v.19, n.3, p.210214, 2012. 
DUARTE, K. V.; MEJIA, D. P. M.. Fisioterapia no trabalho de parto: uma revisão literária. Monografia (Especialização em Uroginecologia, Obstetrícia e Mastologia) - Faculdade Ávila, Goiânia, 2012.

MARCELINO, T. C.; LANUEZ, F. V.. Abordagem

fisioterapêutica na massagem perineal no pré-parto.

ConScientice saúde, v.8, n.2, p.339-344, 2009.

OLIVEIRA, L. M. N.; CRUZ, A. G. C.. A utilização da bola suíça na promoção do parto humanizado. Revista Brasileira de Ciências da Saúde, v.18, n.2, p.175-180, 2014.

PORTO, A. M. F.; AMORIM, M. M. R.; SOUZA, A. S. R.. Assistência ao primeiro período do trabalho de parto baseado em evidências. Femina, v.38, n.10, 2010.
ROMANO, F. B.; MARQUES, A. S. A.; GONZAGA, L. S. V.. Análise da intervenção fisioterapêutica na assistência ao trabalho de parto. Caderno de Ciências Biológicas e da Saúde, Boa Vista, n.2, 2013.

SANTANA, L. S.; GALO, R. B. S.; MARCOLIN, A. C.; FERREIRA, C. H. J.; QUINTANA, S. M.. Utilização dos recursos fisioterapêuticos no puerpério: revisão de literatura. Femina, v.39, n.5, p.245-250, 2011.

SILVA, H. C. F.; LUZES, R.. Contribuição da fisioterapia no parto humanizado: revisão de literatura. Alumni: Revista Discente da UNIABEU, v.3, n.6, p.25-32, 2015.

A CBPC - Companhia Brasileira de Produção Científica (CNPJ: 11.221.422/0001-03) detém os direitos materiais desta publicação. Os direitos referem-se à publicação do trabalho em qualquer parte do mundo, incluindo os direitos às renovações, expansões e disseminações da contribuição, bem como outros direitos subsidiários. Todos os trabalhos publicados eletronicamente poderão posteriormente ser publicados em coletâneas impressas sob coordenação da Sustenere Publishing, da Companhia Brasileira de Produção Científica e seus parceiros autorizados. Os (as) autores (as) preservam os direitos autorais, mas não têm permissão para a publicação da contribuição em outro meio, impresso ou digital, em português ou em tradução. 